\title{
PENGEMBANGAN EKONOMI MASYARAKAT MELALUI PEMBUATAN WA GROUP BISNIS DALAM MENINGKATKAN PEMASARAN IBU-IBU DI PERUMAHAN PURI DEPOK MAS, DEPOK
}

\author{
Laras Cempaka \\ Program Studi IImu dan Teknologi Pangan, Fakultas Teknik dan Ilmu Komputer, \\ Universitas Bakrie, Indonesia \\ E-mail: laras.cempaka@bakrie.ac.id*
}

Received: April 9, 2021 / Revised: May 10, 2021 / Accepted: May 18, 2021

DOI: https://doi.org/10.36782/ijsr.v3i1.80

\begin{abstract}
ABSTRAK
Kegiatan ekonomi dalam masyarakat pada masa pandemi ini perlu ditingkatkan. Diantaranya adalah dengan menggerakkan perekonomian dari kelompok masyarakat kecil pada wilayah perumahan. Aktivitas ekonomi berpeluang sangat besar sekali di lingkungan pemukiman saat ini, terlebih setelah pemerintah mengambil kebijakan PSBB (Pembatasan Sosial Berskala Besar), yang pada akhirnya banyak aktivitas masyarakat yang dialihkan di wilayah tempat tinggal masing-masing. Hal inilah yang menjadi suatu peluang bagi masyarakat sekitar, untuk membangun gairah perekonomiannya. Salah satu strateginya adalah dengan membuatkan suatu wadah dalam rangka meningkatkan pemasaran, meningkatkan kemampuan melalui sesi berbagi ilmu dan saling memutar roda perekonomian diantara sesama. Aktivitas yang dilakukan pada pengabdian ini yaitu dengan membuat komunitas usaha dalam platform WhatsApp Group (WAG) dan mengelola aktivitas bisnis yang ada di dalamnya. Terdapat sekitar 226 warga perumahan Puri Depok Mas (Depok) yang tergabung dalam komunitas ini. Mitra PDM Market yang merupakan komunitas usaha di perumahan tersebut berdiri sejak masa pandemi, dengan beranggotakan para penjual dan pembeli. Penjual didominasi oleh usaha baru, beberapa ada yang berdiri saat masa pandemi. Dengan adanya komunitas usaha melalui WAG ini dapat mengakomodasikan segala kebutuhan penjual terhadap ruang lingkup usahanya maupun kepada pembeli terhadap barang yang dibutuhkannya.
\end{abstract}

Kata kunci: Komunitas Usaha, Perumahan, UMKM, Usaha Kecil, WA Group.

\begin{abstract}
Economic activities in society during this pandemic need to be increased. Among them is by moving the economy from small community groups in residential areas. There is a huge opportunity for economic activity in today's residential areas, especially after the government adopted the PSBB (Large-Scale Social Restriction) policy, which in the end, many community activities were transferred to their respective areas of residence. This is an opportunity for the surrounding community to build their economic passion. One of the strategies is to create a forum in order to improve marketing, increase capabilities through knowledge sharing sessions and rotate the economy between people. The activities carried out in this service area by
\end{abstract}


creating a business community in the WhatsApp group (WAG) platform and managing the business activities in it. There are approximately 226 residents of the Puri Depok Mas (Depok) cluster area who are members of this community. PDM Market Partners, which are business communities in the cluster area, have been established since the pandemic, with members as members of sellers and buyers. Sellers are dominated by new businesses, some of which were established during the pandemic. With the existence of a business community through this WAG, it can accommodate all the needs of the seller with regard to the scope of his business and to the buyer for the goods he needs.

Keywords: Business Communities, Cluster Area, MSMEs, Small Businesses, WA Group.

\section{PENDAHULUAN}

Kondisi perekonomian selama masa pandemi Covid-19 tentu mengalami perubahan yang sangat berarti bagi masyarakat dunia umumnya dan Indonesia khususnya (Wuryandani, 2020; Nasution dkk, 2020; Hadiwardoyo, 2020). Perbaikan roda perekonomian oleh pemerintah mulai ditata dari lini terkecil yaitu rumah tangga. Kondisi pandemi yang dihadapi oleh masyarakat dunia saat ini memberi banyak perubahan dalam tatanan kehidupan. Diantaranya adalah perekonomian, gaya hidup, pola konsumsi, dan lain sebagainya. Beberapa sektor perekonomian banyak yang harus gulung tikar menghadapi arus pandemi ini (Hadiwardoyo, 2020), sehingga banyak karyawan yang dirumahkan. Aktivitas ekonomi berpeluang sangat besar sekali di lingkungan pemukiman saat ini, terlebih setelah pemerintah mengambil kebijakan PSBB (Pembatasan Sosial Berskala Besar), yang pada akhirnya banyak aktivitas masyarakat yang dialihkan di wilayah tempat tinggal masing-masing. Hal inilah yang menjadi suatu peluang bagi masyarakat sekitar, untuk membangun gairah perekonomiannya. Dalam rangka meningkatkan kembali geliat perekonomian rakyat, sektor usaha kecil dan menengah sudah sepatutnya mendapat dukungan total baik dari pemerintah, swasta, masyarakat, maupun stakeholder lainnya. Iklim masyarakat sekitar untuk saling bergotong royong membangun perekonomian perlu ditingkatkan. Salah satunya dengan membangun kesadaran untuk membeli produk lokal masyarakat sekitar. Oleh karena itu, sistem yang baik dan teknologi tepat guna diperlukan untuk membangun ekonomi rakyat. Salah satu perumahan, di wilayah Depok yang cukup besar penduduknya adalah Puri Depok Mas. Komplek tersebut berada di wilayah Kecamatan Pancoran Mas. Terdapat sekitar 500-600 warga yang mendiami perumahan tersebut. Hal inilah yang menjadi alasan untuk memperkuat perekonomian di wilayah tersebut dengan potensi jumlah KK yang besar.

Setiap individu saat ini tidak akan terlepas dari teknologi bernama telepon seluler (Marpaung, 2018). Hampir dipastikan masyarakat usia dewasa memilikinya. Terlebih dengan adanya pandemi seperti saat ini, jaringan 
internet pun menjadi hal yang wajib dimiliki untuk melakukan aktivitas sehari-hari. Oleh karena itu, berkaitan dengan penggiatan ekonomi masyarakat di wilayah sekitar, peluang teknologi informasi yang semakin baik ini sangat mendukung aktivitas bisnis di wilayah perumahan. Tujuan pengabdian ini adalah memudahkan masyarakat melakukan aktivitas perekonomian, membangun semangat berwirausaha dan membuka peluang pemasaran di wilayah perumahan Puri Depok Mas.

\section{METODOLOGI}

Pengabdian dilakukan dengan membuat Whatsapp Group (WAG) dengan nama 'PDM Market'. Penyebaran informasi melalui personal maupun WAG masing-masing RT (RT 01-11), membentuk tim administrasi (admin PDM Market), membuat lembar kuesioner online yang perlu diisi oleh calon anggota sebelum bergabung serta membuat peraturan dalam WAG agar tercipta suasana yang kondusif saat berlangsung proses jual beli. Setelah terkonfirmasi, selanjutnya peserta dapat bergabung di dalam grup. Selain itu, dilakukan pula pengelolaan pada komunitas ini seperti pelatihan dalam platform kuliah whatsapp (kulwap) wirausaha, platform bisnis dan lain-lain, memberi reward kepada peserta yang menyimak dan mengisi form pra dan evaluasi pelatihan, memberi sanksi kepada anggota yang melanggar peraturan, dan pengelolaan layanan dan keluhan anggota untuk menjadi perantara antara penjual maupun pembeli, dan juga mengadakan kegiatan pelatihan-pelatihan terkait dengan (Gambar 1).

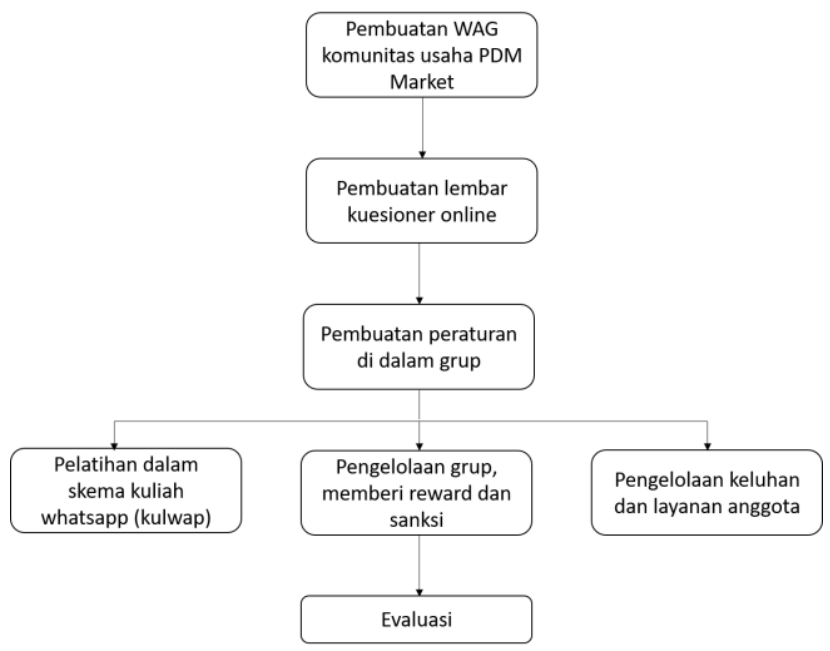

Gambar 1. Diagram Alir Proses Penelitian Komunitas Usaha PDM Market

\section{HASIL DAN PEMBAHASAN}

Terdapat sekitar 226 orang (216 wanita dan 10 pria) yang bergabung ke dalam kelompok WAG Puri Depok Mas. Peserta yang berdomisili di wilayah PDM berjumlah 212 orang. Berdasarkan hasil kuesioner, terdapat 158 penjual dan 194 pembeli (Gambar 2.). Penjualan akan makanan dan minuman sebesar 54\%, disusul oleh produk kosmetika dan kesehatan sebesar $15 \%$, fashion wanita dan pria sebesar $14,2 \%$, serta fashion anak-anak sebesar $11,1 \%$.

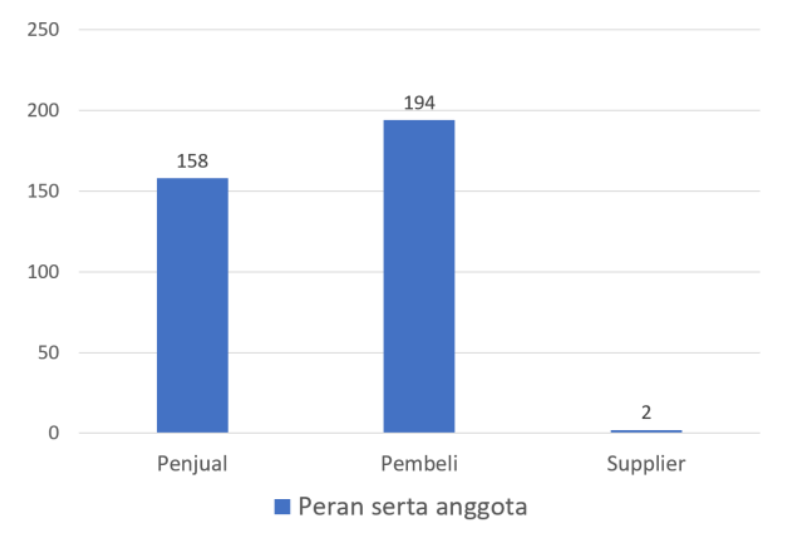

Gambar 2. Peran serta anggota dalam WAG PDM Market 
Produk yang dijual sangat beragam, terdiri dari produk makanan maupun non-makanan (Gambar 3). Produk makanan masih menjadi produk yang dominan diperjualbelikan. Seiring dengan berkembangnya teknologi, dalam memperjualbelikan makanan tentu saja ada beberapa hal yang harus diperhatikan, diantaranya adalah cara produksi pangan yang baik serta keamanan pangan dan keselamatan konsumen. Kualitas produk dengan pemilihan bahan baku yang tepat, rantai pasok pangan yang tidak tepat, pengemasan yang belum baik juga masih menjadi kendala di usaha mikro, kecil dan menengah.

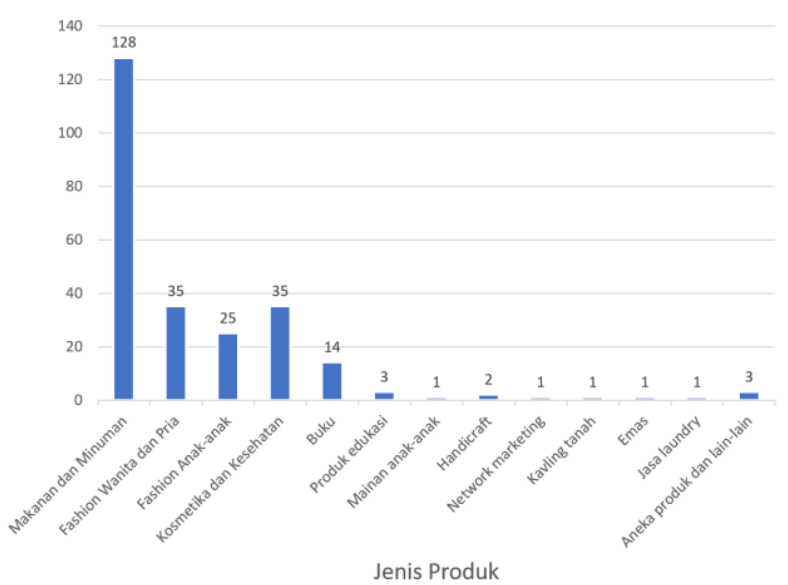

Gambar 3. Jenis produk yang dijual pada WAG PDM Market

Berdasarkan Gambar 4, usia keberjalanan yang dominan berjalan berada diatas 1 tahun. Hal ini menandakan bahwa peserta sebagian besar sudah memiliki usaha sebelum masa pandemi. Namun, sebagian yang lain menyatakan baru memulai kurang lebih 3 bulan, artinya usaha dirintis di saat awal-awal terjadi pandemi Covid-19.

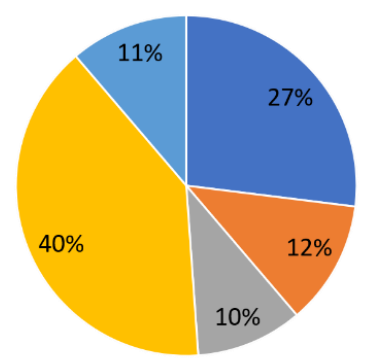

$\begin{array}{ll}\text { - Kurang dari } 3 \text { bulan } & =3<x<6 \text { bulan } \\ \square>1 \text { tahun } & \square \text { Lain-lain }\end{array}$

Gambar 4. Usia Keberjalanan Usaha Anggota WAG PDM Market

Sebagian besar warga yang bekerja dari rumah mendapatkan kesempatan untuk bisa berwirausaha baik menjadi reseller maupun memproduksi sendiri produk jualannya.

Hal yang menarik adalah ketika orang disarankan untuk tetap berada di rumah, membuat seseorang berpikir untuk mencari aktivitas lain yang bermanfaat. Tentu ini menjadi peluang besar untuk bersinergi menghasilkan produk dan memutar roda perekonomian di daerah sendiri. Padahal untuk membentuk suatu tatanan negara yang produktif perlu dimulai dari tatanan masyarakat terkecil. Beberapa masyarakat mulai menemukan hobi barunya, bahkan menjadikannya sebagai sebuah bisnis baru untuk dikembangkan.

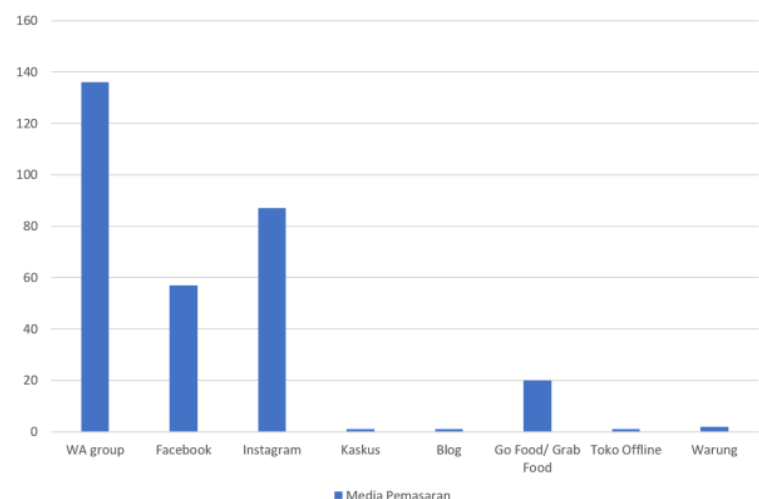

Gambar 5. Media pemasaran yang digunakan oleh anggota WAG PDM Market 
Media pemasaran saat ini lebih banyak menggunakan sistem online (Gambar 5). Pada grup ini banyak yang menggunakan WhatsApp sebagai media untuk memasarkan produknya, disusul oleh Instagram dan Facebook. Terdapat platform lain yang sebelumnya sangat diminati oleh penjual dalam pemasarannya yaitu Kaskus dan blog, namun saat ini banyak yang telah beralih ke platform lain yang populer seperti marketplace misalnya. Selain itu, dengan adanya transportasi online yang juga mengakomodasi pengantaran makanan yaitu Go Food dan Grab Food menjadi pilihan yang menarik. Dengan memanfaatkan media sosial, dapat memangkas biaya pemasaran tetapi dapat menjangkau wilayah yang lebih luas dibandingkan dengan metode konvensional (Suryadi dan Ilyas, 2018; Prapti dan Rahayu, 2018; Setiawan, dkk, 2018; Wahyuni, 2020). Terdapat sekitar 20 responden yang telah berhasil memasarkan via platform tersebut. Selain itu, pada perumahan ini terdapat anggota yang juga membuka warung/toko yang berlokasi sama dengan tempat tinggalnya, namun jumlahnya tidaklah banyak. Hal tersebut dikarenakan pada perumahan ini didominasi oleh kalangan dengan perekonomian yang cukup dan juga beberapa diantaranya adalah ibu dengan status bekerja.

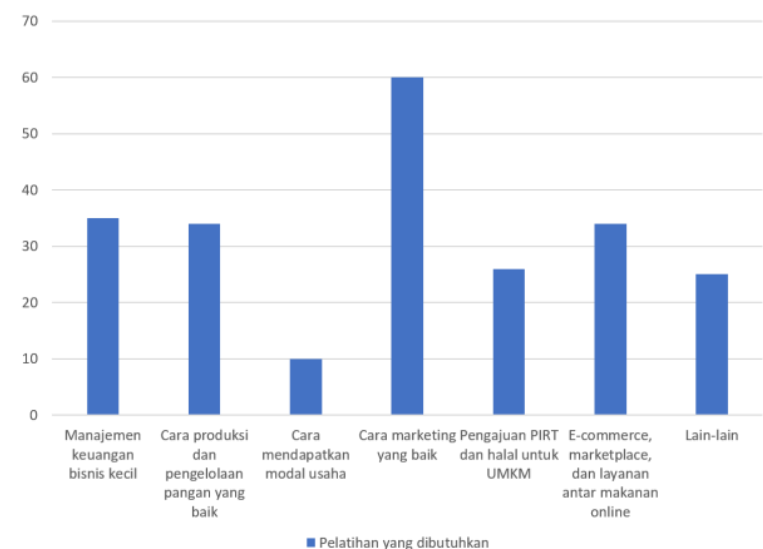

Gambar 6. Pelatihan yang dibutuhkan oleh anggota WAG PDM Market

Permasalahan yang muncul adalah dari sisi pemasaran yang cakupannya belum luas sehingga membuat penjualan tidak banyak berkembang (Taufiq dkk, 2017). Sehingga diperlukan pelatihan untuk meningkatkan kemampuan, kemapanan, dan profesionalitas dalam usaha. Terlihat dari hasil kuesioner, cara marketing yang baik menjadi pilihan yang paling banyak dibutuhkan (Gambar 6). Selain itu, manajemen keuangan bisnis kecil, cara produksi dan pengelolaan pangan yang baik serta layanan e-commerce, marketplace dan transportasi online menjadi topik pelatihan yang dibutuhkan. Dalam mengelola keuangan, kebanyakan pelaku usaha kecil masih mencampurkan antara keuangan pribadi dengan keuangan bisnisnya. Sehingga hal tersebut membiaskan hasil perolehan atau hasil usaha yang dijalani. Usaha yang seharusnya memiliki keuntungan dan dapat memutar kembali modalnya, seolah-olah terlihat rugi atau tidak berkembang. Dengan demikian diperlukan pelatihan untuk manajemen keuangan bisnis kecil. Dengan kedisiplinan untuk 
mencatat, mengatur, dan memisahkan dari keuangan pribadi tentu usaha akan lebih terarah dan lebih mudah untuk dianalisa apakah usaha tersebut sudah membuahkan hasil atau tidak. Namun, tentu saja bukan hanya sekedar pelatihan semata, melainkan harus ada pendampingan untuk mengelola keuangan usaha mikro, kecil dan menengah.

Berdasarkan produk yang dominan dijual yaitu produk makanan, baik makanan siap saji, makanan beku, makanan dalam kemasan, minuman dan lain-lain maka pelatihan mengenai cara produksi yang baik sangat diperlukan. Mengingat saat ini dalam kondisi pandemi, maka setiap orang semakin sadar akan pentingnya kebersihan serta keamanan pangan. Walaupun demikian, kasus covid-19 tidak menular melalui makanan. Dengan kondisi seperti ini sebetulnya menjadikan seseorang lebih bersikap hidup sehat dengan cara menerapkan protokol Kesehatan yang baik. Seperti mencuci tangan yang baik, memakai masker dan menjaga jarak. Hal ini sudah menjadi dasar dalam penerapan pengolahan pangan. Hal lain yang perlu diterapkan dalam pelatihan adalah 4 dasar berikut yaitu mencuci tangan yang baik dan benar; memisahkan peralatan, wadah maupun bahan baku serta produk makanan; memasak makanan secara matang sempurna; dan menyimpan makanan pada suhu dingin contohnya pada kulkas. Selain itu, e-commerce, marketplace dan transportasi makanan online saat ini menjadi pilihan yang tepat dalam memasarkan produk secara online (Jauhari, 2010; Magdalena, 2017). Namun, belum banyak yang mengetahui tata cara untuk mendaftarkan usahanya pada platform tersebut.

Dari hasil kuesioner tersebut, makan diperoleh garis besar pelatihan sebagai berikut:

Kelompok pertama yaitu Kelompok Usaha Umum Menyeluruh, diperlukan pelatihan untuk meningkatkan gairah berwirausaha dengan mengusung tema penguatan karakter kewirausahaan dan etika berbisnis di lingkungan Puri Depok Mas. Dikarenakan sesuai dengan tujuan pemerintah untuk meningkatkan kembali gairah berwirausaha di lingkungan masyarakat (Wuryandani, 2020). Selain itu, pelatihan manajemen usaha, keuangan dan branding diperlukan untuk meningkatkan kemampuan berwirausaha. Terkadang bukan karena tidak ada keinginan untuk bisa melakukan wirausaha, tetapi tidak adanya pengetahuan dan kemampuan untuk melakukan manajemen usaha, keuangan maupun branding produk.

Kelompok Kedua, Kelompok Usaha Produksi Makanan, pada standar sanitasi dan higienis yang baik dalam produksi pangan dan juga cara produksi pangan yang baik. Terkadang untuk usaha mikro maupun usaha kecil masih belum menerapkan standar higienis yang baik. Selain karena minimnya pengetahuan, sikap maupun praktiknya terhambat karena kurangnya modal untuk mewujudkan proses pengolahan yang higienis seperti menyiapkan sink untuk mencuci peralatan dan bahan yang bersih, sarana 
mencuci tangan yang baik, menggunakan masker, menyatakan ragu-ragu dan tidak hal itu sarung tangan dan penutup kepala bagi pekerja, dikarenakan anggota masih bersifat sebagai dan lain sebagainya. Tentu hal ini pun harus didukung oleh modal yang memadai (Cempaka, dkk, 2019). Selain itu, proses pengemasan, prediksi masa simpan yang baik perlu disosialisasikan agar makanan dapat dipertahankan kualitasnya.

Kelompok ketiga, Kelompok Reseller Usaha Makanan Dan Minuman, memberikan kemampuan digital marketing yang baik untuk meningkatkan penjualan diantaranya adalah mengoptimalkan potensi WA bisnis, digital marketing melalui media sosial, marketplace, khusus untuk produk pangan dengan transportasi online seperti Go Food dan Grab Food. Permasalahan dari usaha mikro dan kecil lainnya adalah kurangnya strategi pemasaran atau kurangnya pengetahuan untuk menggunakan platform bisnis yang sebetulnya sudah ada dan tersedia. Sehingga diperlukan pendampingan untuk membantu upaya tersebut.

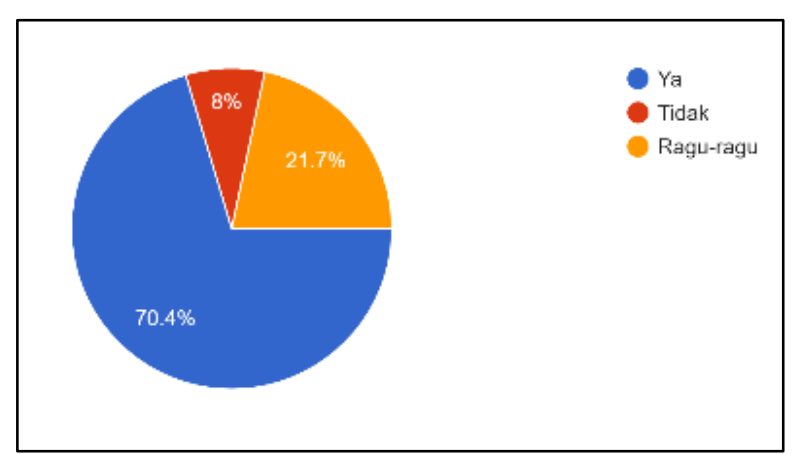

Gambar 7. Ketertarikan anggota WAG PDM Market terhadap penyelenggaraan pelatihan

Pada pertanyaan tertutup (Gambar 7) hasilnya adalah sebagian besar anggota menyetujui diadakan pelatihan. Untuk yang pembeli atau merasa belum mmebutuhkan suatu pelatihan.

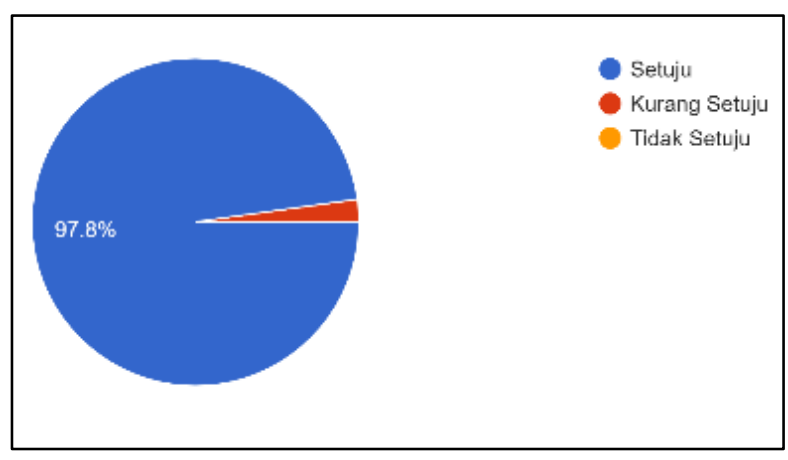

Gambar 8. Tanggapan anggota WAG PDM Market terhadap peraturan yang dibuat oleh tim admin

Pada keberjalanan WAG PDM Market ini, tim admin yang terdiri dari 5 orang membuatkan peraturan yang wajib ditaati oleh semua anggota.

Diantaranya adalah kuantitas posting foto maks 3 foto (termasuk foto collage) dalam tiap sesi secara berurutan, meminta untuk semua penjual melakukan transaksi secara jujur dan amanah, tidak membuat postingan berbau sara, atau perselisihan, grup khusus dibuat untuk berdagang dan hal yang berkaitan dengan aktivitas berdagang, jam posting dibuat seperti keterangan yang terdapat pada Gambar 9, penjual disarankan mencantumkan harga produk yang dijual, penjual yang melakukan tiga kali pelanggaran maka akan dikenakan sanksi tidak dapat posting selama $2 \times 24$ jam. 


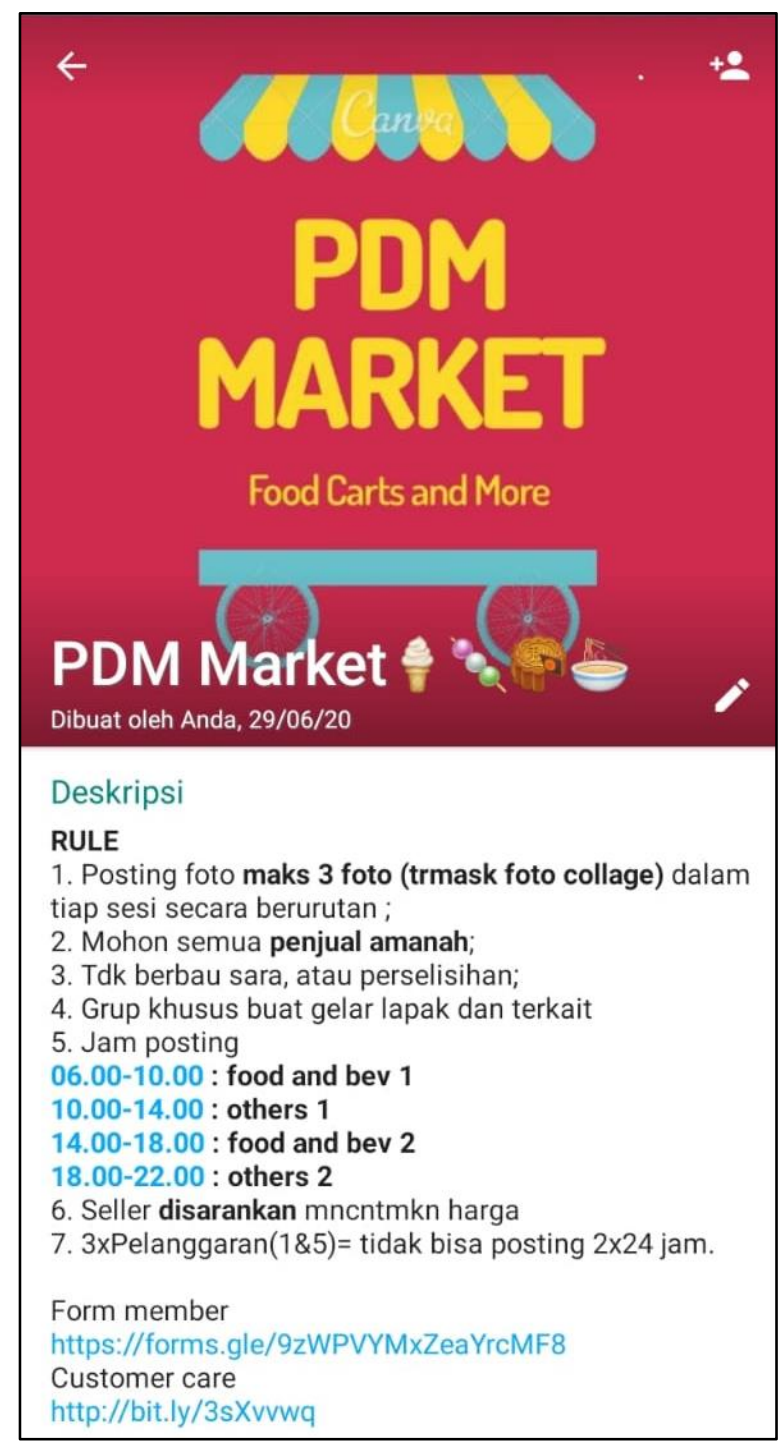

Gambar 9. Kolom Dashboard WAG PDM Market

Berdasarkan aktivitas yang telah dilakukan, ada beberapa kasus pelanggaran yang terjadi, yaitu mengenai jam posting. Penjual yang melanggar misalnya ketika penjual makanan dan minuman memposting di jam yang lain atau di luar jam yang telah ditentukan (Gambar 9). Pemberian sanksi untuk yang melanggar sebanyak tiga kali adalah tidak dapat berjualan selama 2 hari berturut-turut. Dengan adanya hukuman ini membuat anggota menjadi lebih hati-hati ketika memposting produk jualannya.
Hal ini pun berguna agar anggota lain tidak memberatkan ruang memori gawai mereka

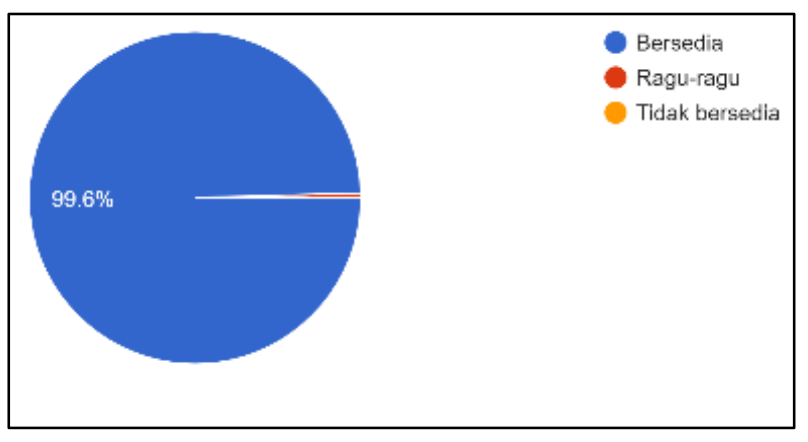

Gambar10. Kesediaan anggota WAG PDM Market dalam mentaati peraturan

Pada Gambar 10. Menunjukkan keseluruhan anggota mau mentaati peraturan yang berlaku. Hal tersebut menjadi komitmen para anggota PDM Market untuk saling mengingatkan jika ada yang melakukan kesalahan atau pelanggaran. Terlebih komunitas ini mengutamakan sifat persaudaraan diantara sesama warga.

\section{KESIMPULAN}

Dari hasil penelitian, diperoleh bahwa media sosial menjadi bagian yang tidak terpisahkan dari kehidupan saat ini, termasuk dalam fasilitas dalam kegiatan ekonomi. Melalui WAG, dapat mempermudah sistem pemasaran yang dilakukan dalam ruang lingkup skala kecil seperti usaha yang berkembang di masyarakat saat ini. Dengan dibentuknya WAG PDM Market ini pun, dapat mempererat silaturahmi antara warga PDM, meningkatkan semangat untuk berdagang, menjadi media dalam pemasaran, serta dapat mengaktifkan pelatihan-pelatihan yang diperlukan dalam melakukan usaha. 


\section{UCAPAN TERIMA KASIH}

Terima kasih kepada admin WAG bisnis Puri Depok Mas atas bantuan dan kerjasama secara teknis dalam kepengurusan WAG ini.

\section{DAFTAR PUSTAKA}

Cempaka, L., Rizki, A.A., \& Asiah, N. (2019). Knowledge, Attitudes and Practices Regarding Food Hygiene and Sanitation of Food Street Handlers in The Public Elementary School, At Greater Jakarta, Indonesia. Asia Pacific Journal of Sustainable Agriculture Food and Energy (APJSAFE), 7 (2), $1-8$.

Hadiwardoyo, W. (2020). Kerugian Ekonomi Nasional Akibat Pandemi Covid-19). Baskara: Journal of Business \& Entrepreneurship Universitas Muhammadiyah Jakarta, 2(2), 83-92.

Jauhari, J. (2010). Upaya Pengembangan Usaha Kecil dan Menengah (UKM) dengan Memanfaatkan E-Commerce. Jurnal Sistem Informasi (JSI), 2 (1), 159-168.

Magdalena, H., \& Ellyani, W. (2017). Strategi Memanfaatkan E-Commerce dalam Memasarkan Makanan Khas Bangka (Studi Kasus: Aneka Citra Snack). Cogito Smart Journal, 3(2), 286-298.

Marpaung, J. (2018). Pengaruh Penggunaan Gadget Dalam Kehidupan. Jurnal Kopasta, $5(2), 55-64$.

Nasution, D. A. D., Erlina, E., Muda, I. (2020). Dampak Pandemi Covid-19 terhadap
Perekonomian Indonesia. Jurnal Benefita, $5(2), 212-224$.

Prapti, R. L. \& Rahoyo. (2018). Dampak Bisnis Kuliner Melalui Go Food Bagi Pertumbuhan Ekonomi di Kota Semarang. Dinamika Sosial Budaya, 20, 120-133.

Setiawan, T. F., Suharjo, B., \& Syamsun, M. (2018). Strategi Pemasaran Online UMKM Makanan

(Studi Kasus di Kecamatan Cibinong). Manajemen IKM, 116-126.

Suryadi, D. F., \& Ilyas, M. I. F. (2018). Adopsi Online Food Delivery Service Bagi Wirausaha Pemula di Kota Makasar (Studi Kasus Pada Big Bananas). Prosiding Seminar Hasil Penelitian (SNP2M), 75-80.

Taufiq, R., \& Jatmika, D. (2016). Masalah yang dihadapi Usaha Kecil Menengah di Indonesia. El-Ecosy, Jurnal Studi Ekonomi Syariah, 2(6). Wahyuni, S. (2020). Analisis Dampak Keberadaan Go Food dan Grab Food terhadap Peningkatan Penjualan Usaha Kuliner [Skripsi]. Universitas Islam Negeri Sumatera Utara. Medan.

Wuryandani, D. (2020). Dampak Pandemi Covid19 terhadap Pertumbuhan Ekonomi Indonesia 2020 dan Solusinya. Bidang Ekonomi dan Kebijakan Publik, Info Singkat, Kajian Singkat terhadap Isu Aktual dan Strategis. Pusat Penelitian Badan Keahlian $D P R R I, 19-24$. 